\title{
AS INTENÇÕES DOS ATORES E OS RESULTADOS DA IMPLANTAÇÃO DO SISTEMA ELEITORAL MISTO NA VENEZUELA
}

\author{
João Carlos Amoroso Botelho
}

\begin{abstract}
RESUMO
Este artigo avalia se a adoção de um sistema eleitoral misto para a câmara baixa na Venezuela, a partir das eleições de 1993, alcançou os resultados esperados pelos principais atores que participaram dos processos de sua idealização e de sua implantação. Não há a intenção de advogar por este ou aquele sistema eleitoral nem de apontar as vantagens e as desvantagens de cada tipo. O objetivo é unicamente avaliar os resultados de um caso de adoção de um sistema misto e contrapô-los às expectativas dos atores. É apenas com uma análise rigorosa nesse sentido que se pode saber se, na prática, as expectativas cumpriram-se ou frustraramse. Uma avaliação de antemão também seria possível, mas não teria a sustentação empírica que confere um exercício como o deste trabalho. Um artigo que contraponha as intenções dos atores com os resultados da implantação de um sistema misto é importante porque, como se trata de uma fórmula menos comum cujos resultados são pouco conhecidos fora dos círculos mais especializados, sua adoção é vista em muitos países, mesmo no Brasil, como a solução para os problemas identificados nas regras vigentes. O que se tentará mostrar aqui, com base no exemplo venezuelano, é que na prática pode não ser sempre assim. A hipótese de trabalho é que as expectativas viram-se frustradas, tanto da parte dos que buscavam diminuir a influência dos partidos sobre a definição dos candidatos e dos parlamentares eleitos a cada votação e ainda sobre a atuação dos seus deputados, quanto da parte das agrupações políticas tradicionais que pretendiam manter-se como dominantes.
\end{abstract}

PALAVRAS-CHAVE: Venezuela; sistemas eleitorais mistos; intenções dos atores; câmara baixa.

\section{INTRODUÇÃO}

O objetivo deste artigo é avaliar se a adoção de um sistema eleitoral misto para a câmara baixa na Venezuela, a partir das eleições de 1993, alcançou os resultados esperados pelos principais atores que participaram dos processos de sua idealização e implantação.

Não há a intenção de advogar por este ou aquele sistema eleitoral nem de apontar as vantagens e as desvantagens de cada tipo. O objetivo é unicamente avaliar os resultados de um caso de adoção de um sistema misto e contrapô-los às expectativas dos atores. É apenas com uma análise rigorosa nesse sentido que se pode saber se, na prática, as expectativas cumpriram-se ou frustraram-se. Uma avaliação de antemão também seria possível, mas não teria a sustentação empírica que confere um exercício como ao que este trabalho propõe-se.

Um artigo que contraponha as intenções dos atores com os resultados da implantação de um sistema misto é importante porque, como se trata de uma fórmula menos comum cujos resultados são pouco conhecidos fora dos círculos mais especializados, sua adoção é vista em muitos países, mesmo no Brasil, como a solução para os problemas identificados nas regras vigentes. O que se tentará mostrar aqui, com base no exemplo venezuelano, é que na prática pode não ser sempre assim.

A hipótese de trabalho é que as expectativas viram-se frustradas, tanto da parte dos que buscavam diminuir a influência dos partidos sobre a definição dos candidatos e dos parlamentares eleitos a cada votação e ainda sobre a atuação dos seus deputados, quanto da parte das agrupações políticas tradicionais que pretendiam manter-se como dominantes.

Entre 1959, quando tomou posse o primeiro governo de seu atual período democrático, e 1993, a Venezuela foi administrada por apenas dois partidos: a Ação Democrática (AD), social-democrata, e o Comitê de Organização Política Eleitoral 
Independente (Copei), social-cristão. O sistema partidário do país passou a caracterizar-se de maneira mais marcante pelo bipartidarismo a partir do começo da década de 1970, situação só atenuada pela existência de uma terceira força, o Movimento ao Socialismo (MAS), que conseguiu manter representação parlamentar ao longo desse período dominado por $\mathrm{AD}$ e Copei.

No início dos anos 1980, porém, a Venezuela começou a enfrentar sérias dificuldades econômicas, devido à queda dos preços do petróleo, que haviam passado por um vertiginoso aumento na década anterior, e das dívidas externas contraídas no período de euforia. Caballero (2003) vê no episódio da desvalorização de 1983, conhecido como Sexta-Feira Negra, um sinal do esgotamento do modelo econômico baseado unicamente na renda petroleira. Sob a influência da situação econômica, o sistema bipartidário deu os primeiros sinais de crise ainda nos anos 1980 .

Em 1989, o aumento do custo do transporte público, gerado pela elevação do preço da gasolina como parte de um pacote de reformas neoliberais anunciado pelo então Presidente Carlos Andrés Pérez (AD), motivou a explosão de uma revolta popular em Caracas, que ficou conhecida como "Caracaço", que deixou um saldo de 270 mortos, segundo a contagem oficial. Em 1992, houve duas tentativas de golpe militar contra o mesmo mandatário e, no ano seguinte, um processo de impedimento que o destituiu do cargo por acusações de corrupção.

A literatura (CABALLERO, 2003; HELLINGER, 2003) é coincidente ao afirmar que a gestão Carlos Andrés Pérez marcou o fim de um modelo político, definido por Rey (1972) como um sistema populista de reconciliação, baseado na distribuição dos benefícios da renda petroleira por meio do clientelismo.

Para Maingon (2004), o processo que levou ao fim do bipartidarismo pode ser dividido em três crises simultâneas: a da representação baseada nos partidos tradicionais; a do Estado, diante das dificuldades econômicas e da queda da renda petroleira, o que afetou a capacidade de as forças dominantes sustentarem suas redes clientelistas de distribuição de benefícios; a de legitimidade do regime democrático que vigorava no país, em conseqüência das outras duas. Há ainda os fatores externos que afetaram, a partir do âmbito mundial, os partidos.
Uma combinação de crises econômica e política, portanto, contribuiu para a formação de um alto grau de insatisfação com o domínio exercido por AD e Copei. Nesse contexto foi idealizado e adotado um sistema eleitoral misto. As eleições parlamentares de 1993 foram as primeiras em que a câmara baixa passou a ser definida por uma combinação de representação proporcional e distritos nominais com regra majoritária, a modalidade introduzida. A próxima parte deste artigo tratará de descrever o sistema implantado.

\section{O SISTEMA ELEITORAL MISTO VENEZUE- LANO}

A fórmula mista foi adotada até 1998 para a Câmara dos Deputados e, a partir de 2000, começou a valer para a Assembléia Nacional, que virou a única Casa do Parlamento com a Constituição de 1999. Na primeira votação sob o novo método, em 1993, a divisão, em geral, foi de 50\% das cadeiras de deputados disputadas pelo sistema que vigorava até então (a representação proporcional com listas fechadas), enquanto os outros 50\% ficaram para os distritos uninominais com regra majoritária. Cada eleitor ganhou o direito de ter dois votos para esse cargo, um para o candidato nominal em seu distrito e o outro para a lista partidária no seu estado. Também foi a primeira vez em que a escolha dos deputados ocorreu em uma cédula separada. Até então, o eleitor tinha que optar pelo mesmo partido para a Câmara dos Deputados, para o Senado e para a Assembléia Estadual porque, com uma única cédula representando cada agremiação, votava para as três instituições.

A divisão entre distritos nominais e representação proporcional não era de 50\% para cada sistema em todos os casos. Se a unidade da federação (estados e Distrito Federal) tinha direito a um número ímpar de representantes, a parte maior em 1993 ficava para a disputa nos distritos com regra majoritária. $\mathrm{O}$ total de vagas por unidade territorial continuou a obedecer à norma que vigorava, pela qual cada $0,55 \%$ da população do país vale um posto. A novidade introduzida foi a fixação de um número mínimo de três deputados, o que significou a super-representação de estados menos populosos (CRISP \& REY, 2001, p. 188).

A distribuição das cadeiras passou a funcionar da seguinte maneira: 1) é feita a divisão por partido em nível estadual a partir dos votos em lista e 
com base na representação proporcional pela fórmula d'Hondt ${ }^{1}$; 2) contabiliza-se o número de eleitos por partido pela disputa nominal; 3) esse número é descontado das vagas obtidas na votação por lista; 4) quando o partido elege menos deputados na disputa nominal que a sua votação por lista proporciona-lhe, os postos restantes são preenchidos pelos nomes da lista em ordem de aparição; 5) quando elege mais pelo sistema nominal, todos estão garantidos. As cadeiras adicionais continuaram a ser distribuídas de acordo com o total de votos recebidos pelo partido nacionalmente, com a diferença de que o número máximo de vagas extras por agremiação política subiu de quatro para cinco.

Devido à regra que desconta os candidatos eleitos nominalmente dos que a lista confere ao partido, uma forma de burlar isso acabou sendo adotada. Ela é conhecida na Venezuela como "partidos morochos”, que consiste em lançar concorrentes nas disputas nominais por agrupações auxiliares, para que a força principal não tenha diminuído o número de eleitos por sua lista e, assim, obtenha uma bancada maior, reunindo os eleitos pelos dois sistemas.

A lei foi modificada antes que pudesse ser utilizada uma segunda vez em 1998. Assim, para as eleições daquele ano, no caso de unidades da federação com um número ímpar de representantes na câmara baixa, a parte maior das vagas deixou de ficar para a votação nos distritos nominais e foi para a disputa de representação proporcional; também foi extinta a correção da proporcionalidade no caso de um partido obter mais eleitos pelo sistema nominal do que sua lista permitir-lhe-ia. Esses postos passaram a ser retirados das agrupações com os totais de votos menores para suas listas.

Outra mudança ocorreu na magnitude dos distritos nominais. Para evitar a divisão de uma cidade em mais de uma circunscrição, criou-se uma fórmula em que os municípios são agrupados com base na divisão da população do estado pelas cadeiras em disputa nos distritos nominais, o que significou o surgimento de circunscrições

1 Cada vaga de deputado fica com a lista partidária, cujo total de votos dividido pelos números inteiros sucessivos, começando pelo 1, seja maior. O processo de divisão prossegue até que todas as vagas sejam preenchidas. Em caso de igualdade em qualquer quociente, a cadeira é atribuída à lista menos votada. multinominais. Nesse caso, os partidos ganharam o direito de ter tantos candidatos quanto as vagas em disputa, e os eleitores, tantos votos quantas vagas houvesse na competição. A nova lei não fixou um limite para a variação do tamanho dos distritos.

Uma última alteração foi em relação à simultaneidade das eleições. As votações para a Câmara dos Deputados, para o Senado, para os governos dos estados e para as assembléias estaduais foram antecipadas em um mês e as para as prefeituras e os conselhos municipais, atrasadas em cerca de um semestre. A disputa presidencial foi, então, mantida isolada em sua data original.

Com a Constituição de 1999, além da já mencionada extinção do Senado, as eleições parlamentares e presidenciais foram inicialmente reagrupadas em 2000, para, a partir de então, passarem a coincidir apenas a cada 30 anos, pois o mandato do Presidente foi aumentado de cinco para seis anos, enquanto o dos deputados foi mantido em cinco. Já o tamanho da câmara baixa, agora chamada de Assembléia Nacional, foi reduzido $^{2}$ - pois a divisão por estados passou a obedecer à norma de cada $1,1 \%$ da população nacional representar uma vaga, além de três postos fixos por unidade territorial. Houve ainda a fixação de uma cota de três representantes indígenas.

Duas mudanças adicionais foram a extinção da distribuição de cadeiras extras com base na votação nacional e a divisão do sistema misto de eleição dos deputados em $60 \%$ para os distritos nominais e $40 \%$ para a representação proporcional. Finalmente, encerrando a descrição, as agrupações políticas começaram a ter de realizar disputas internas para a seleção dos candidatos e a destinar $30 \%$ das vagas em suas listas para mulheres.

Uma particularidade do conteúdo político da nova Constituição é ilustrativa do sentimento antipartidos que se disseminara no país. A palavra "partido" (assim como o conceito de representação), desapareceu do texto constitucional, sendo substituída pela expressão "associações com fins políticos” (ÁLVAREZ, 2003, p. 193-194).

\footnotetext{
2 Em 2000, a composição ficou em 165 cadeiras; na eleição seguinte, em 2005, subiu para 167.
} 


\section{AS INTENÇÕES DOS ATORES}

As reformas política e eleitoral na Venezuela ganharam impulso a partir do final dos anos 1970, quando as eleições municipais (para conselhos e prefeituras) tornaram-se independentes das demais e foi instituída a votação direta para prefeitos. Dez anos depois, as eleições estaduais (para assembléias e governos) também foram separadas da disputa nacional, assim como os governadores começaram a ser definidos diretamente pela população. Satisfeitas essas demandas, mais relacionadas com a estrutura política do Estado e com a divisão de poderes, as organizações da sociedade civil, sobretudo associações de bairros, concentraram-se na influência dos partidos sobre a definição dos candidatos que entram na disputa e dos parlamentares eleitos a cada votação, já que, com a utilização das listas fechadas, são as agrupações políticas que estabelecem os nomes da relação e a sua ordem de aparição.

As intenções desses grupos que nos interessam aqui, com a modificação do sistema eleitoral, eram diminuir o poder dos partidos sobre as candidaturas a Deputado Federal e o resultado final e, com isso, aumentar a capacidade de o eleitorado julgar e punir os parlamentares e tornar os eleitos mais sensíveis às demandas dos votantes que representam e dos cidadãos em geral.

Entre as forças tradicionais, as intenções variaram ao longo do processo de negociação e implantação da reforma eleitoral. O Copei, até mesmo em virtude da proximidade com os democratocristãos da Alemanha, onde o sistema é misto, sempre defendeu essa fórmula, considerando que seria a melhor maneira de aceitar as demandas por mudança e, ao mesmo tempo, preservar o poder dos partidos sobre as candidaturas e o domínio das duas agrupações tradicionais.

A AD foi inicialmente contra alterar o sistema de representação proporcional que vigorava, já que, com sua a utilização, fôra a força política dominante no país. Com a continuidade das crises eco-

\footnotetext{
3 O principal interesse das tabelas 1 e 3 é exibir a variação dos votos da $\mathrm{AD}$ e do Copei antes e depois da adoção do sistema misto. Por isso, essas tabelas não indicam cada um
}

nômica e de credibilidade política, porém, acabou concordando com um certo grau de modificação e com a proposta do Copei de adotar uma fórmula mista, pois acreditava que tinha as vantagens de ser similar à que era utilizada e de não introduzir a competição intrapartidária na definição das candidaturas. Assim, os socialdemocratas pretendiam defender seu domínio sobre o cenário partidário venezuelano.

Já as forças políticas minoritárias de esquerda buscavam a manutenção da representação proporcional, por ser o sistema mais propício aos partidos menos significativos, e o aumento da influência dos eleitores sobre o resultado final por meio da troca das listas fechadas por abertas. As agrupações minoritárias de direita, por sua vez, defendiam a implantação da fórmula majoritária. As intenções desses dois grupos não são confrontadas aqui com os resultados da adoção do sistema misto porque, como não tiveram suas posições principais contempladas na reforma, já terminaram o processo derrotados.

\section{RESULTADOS VERSUS INTENÇÕES}

As primeiras eleições com o sistema misto já começaram a mostrar que ele não ajudaria a manter o domínio dos dois partidos tradicionais sobre a câmara baixa do parlamento (ver Tabela $1^{3}$ ) e o cenário político em geral: na disputa anterior, em 1988, AD e Copei obtiveram 74,3\% dos votos em listas; na de 1993 , caíram para $46 \%$ e continuaram em queda nas duas seguintes, de 1998 e 2000, com $36,1 \%$ e $21,2 \%$, respectivamente. Na última disputa, de 2005, retiraram-se, como os demais partidos de oposição ao governo Chávez, sob a alegação de que o Conselho Nacional Eleitoral (CNE) não é imparcial. Assim, não há resultados de AD e Copei nessa votação. Também não foi possível incluir na tabela as porcentagens em nível nacional dos partidos que concorreram em 2005, pois ainda não estavam disponíveis para consulta no portal eletrônico do CNE.

dos partidos incluídos na categoria "Outros”, exceto nas situações em que isso é relevante, ou seja, a partir das primeiras eleições sob o novo sistema. 
TABELA 1 - RESULTADOS DAS ELEIÇÕES PARLAMENTARES NA VENEZUELA (EM \%)

\begin{tabular}{|c|c|c|c|c|c|}
\hline AnOS & ADECOPEI & OUTROS & CONVERGEHCIA & $\begin{array}{c}\text { IOR(ACALSA } \\
\text { RATCA) }\end{array}$ & $\begin{array}{l}\text { MLRADWHEKTOQWNTA } \\
\text { REFÍBACA }\end{array}$ \\
\hline $\begin{array}{l}1968 \\
1063\end{array}$ & 64,7 & 35,5 & - & - & - \\
\hline 1963 & 53,5 & 46,5 & - & - & - \\
\hline 1968 & 49,5 & 50,4 & - & - & - \\
\hline 1973 & 74,7 & 25,3 & - & - & - \\
\hline 1978 & 79,5 & 20,5 & - & - & - \\
\hline 1983 & 78,6 & 21,4 & - & - & - \\
\hline 1968 & 74,3 & 25,7 & - & - & - \\
\hline 1993 & 46,0 & 19,5 & 13,8 & 20,7 & - \\
\hline 1998 & 36,1 & $38,6^{\star}$ & 2,5 & 2,9 & 199 \\
\hline 2000 & 21,2 & $289^{* *}$ & 1,1 & 4,4 & 44,4 \\
\hline $2005^{* \star *}$ & $\star \star \star \star \star \star *$ & & & & \\
\hline
\end{tabular}

FONTE: o autor, a partir de Maingon (2004).

NOTAS: 1. * Distribuídos, sobretudo, entre PRVZL (Projeto Venezuela), MAS e PPT (Pátria para Todos).

2. ** Distribuídos, sobretudo, entre PRVZL, MAS, MPJ (Movimento Primeiro Justiça) e PPT.

3. ${ }^{\star \star \star} A s$ porcentagens por partido em nível nacional ainda não estavam disponíveis.

4. ${ }^{* \star \star \star} A D$, Copei e demais partidos de oposição retiraram-se da disputa.

O mesmo resultado inverso ao que esperavam as duas forças tradicionais ocorreu com o número efetivo de partidos nas eleições parlamentares (ver Tabela 2). Ele saltou de 2,24 em 1988 para 4,88 em 1993; voltou a subir na disputa seguinte, para 7,60, e caiu bastante em 2000, para 4,30, mas ainda com um valor que é quase o dobro do registrado nas últimas eleições antes do sistema misto. Para a edição de 2005, ainda não é possível fazer o cálculo, pelo motivo explicado acima. De qualquer forma, sua representatividade é menor, já que um dos pólos do sistema partidário não participou da disputa.

TABELA2 - NÚMERO EFETIVO DE PARTIDOS NAS ELEIÇÕES PRESIDENCIAIS E PARLAMENTARES NA VENEZUELA

\begin{tabular}{|l|c|c|}
\hline ANOS & PRESIDENCIAIS & PARLAMENTARES \\
\hline 1958 & 1,91 & 1,83 \\
\hline 1963 & 3,30 & 1,33 \\
\hline 1968 & 3,90 & 4,66 \\
\hline 1973 & 1,96 & 2,12 \\
\hline 1978 & 2,21 & 2,66 \\
\hline 1983 & 1,62 & 1,79 \\
\hline 1988 & 1,83 & 2,24 \\
\hline 1993 & 4,80 & 4,88 \\
\hline 1998 & 6,40 & 7,60 \\
\hline 2000 & 3,40 & 4,30 \\
\hline 2005 & - & $\star$ \\
\hline 2006 & 4,70 & - \\
\hline
\end{tabular}

FONTE: o autor, a partir de Maingon (2004).

NOTA: * As porcentagens por partido em nível nacional ainda não estavam disponíveis.

\footnotetext{
4 Em 1998, a AD abandonou seu candidato para apoiar
}

Outro indicador do fracasso da tentativa de o Copei e a AD manterem-se como dominantes por meio do sistema eleitoral é a evolução do seu desempenho nas eleições presidenciais (ver Tabela 3). Na disputa pelo máximo cargo nacional, foi mantida a fórmula majoritária com um único turno. Apesar disso, os partidos tradicionais amargaram em 1993 a primeira derrota desde 1958 e não voltaram mais sequer a ter candidatos próprios ${ }^{4}$. Nas eleições anteriores à primeira derrota, AD e Copei haviam obtido 88\% dos votos para Presidente; nas de 1993, a última com chapas próprias, caíram para 46,3\%. Esses números mostram que mesmo a manutenção das regras não foi capaz de frear a queda.

\begin{tabular}{|c|c|c|c|c|c|}
\hline ANOS & $\begin{array}{c}\text { ADE } \\
\text { COPEI }\end{array}$ & OUTROS & $\begin{array}{l}\text { CONVER- } \\
\text { GENCIA }\end{array}$ & LCR & MUR \\
\hline 1958 & 96,9 & 3,1 & & & \\
\hline 1963 & 64,4 & 35,6 & & & \\
\hline 1968 & 53,0 & 47,0 & & & \\
\hline 1973 & 56,3 & 43,7 & & & \\
\hline 1978 & 84,0 & 16,0 & & & \\
\hline 1983 & 88,6 & 11,4 & & & \\
\hline 1988 & 88,0 & 12,0 & & & \\
\hline 1993 & 46,3 & 1,2 & 30,5 & 22,0 & \\
\hline $1998^{*}$ & & $43,7^{* \star}$ & & 0,1 & 56,2 \\
\hline $2000^{*}$ & & 2,7 & & 37,5 & 59,8 \\
\hline $2006^{*}$ & & $37,2^{* * *}$ & & & 62,8 \\
\hline
\end{tabular}

FONTE: o autor, a partir de Maingon (2004).

NOTAS: $1 .{ }^{*} A D$ e Copei não tiveram candidatos próprios. 2. ** O candidato do PRVZL ficou com $40,0 \%$.

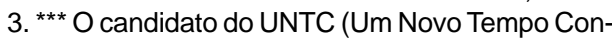
tigo) ficou com $36,9 \%$

Henrique Salas Romer, o concorrente mais próximo de Hugo Chávez na reta final. 
Na disputa pelos governos estaduais, iniciada em 1989, a decadência das forças tradicionais também foi marcante e até mais abrupta (ver Tabela 4). A AD e o Copei elegeram naquele ano 17 dos 20 governadores e, na edição seguinte, já em 1992, os mesmos 17 entre 22. A perda de espaço ainda não foi tão grande quanto a partir de 1998, quando ficaram com 13 das 23 administrações; a partir daí, os resultados desabaram até chegar, em 2004, a apenas um governo, da AD, entre 23.

TABELA 4 - NÚMERO DE GOVERNADORES NA VENEZUELA(POR PARTIDO E POR ANO DE ELEIÇÃO)

\begin{tabular}{|c|c|c|c|c|c|c|}
\hline PARTIDO & 1989 & 1992 & 1995 & 1998 & 2000 & 2004 \\
\hline AD & 11 & 8 & 12 & 8 & 2 & 1 \\
\hline Copei & 6 & 9 & 3 & 5 & 1 & \\
\hline MAS & 2 & 4 & 4 & 3 & 3 & \\
\hline LCR & 1 & 1 & 1 & & & \\
\hline Convergencia & & & 1 & 1 & 1 & \\
\hline MVR & & & & 4 & 12 & 14 \\
\hline PRZVL & & & & 1 & 1 & \\
\hline PROCA & & & 1 & & & \\
\hline MERI & & & & 1 & & \\
\hline PPT & & & & & 2 & 2 \\
\hline Podemos & & & & & & 3 \\
\hline MiGato & & & & & & 1 \\
\hline MiGente & & & & & & 1 \\
\hline UNTC & & & & & 1 & 1 \\
\hline Total & 20 & 22 & 22 & 23 & 23 & 23 \\
\hline
\end{tabular}

FONTE: o autor, a partir de Maingon (2004).

NOTA: não se considerou nesta tabela o Distrito Federal.

Os partidos tradicionais, portanto, viram frustrada a intenção de, com um nível menor de mudança no sistema eleitoral e a implantação da fórmula mista, preservarem suas posições dominantes. O único objetivo que conquistaram foi manter o controle interno sobre as candidaturas a Deputado Federal. Isso, porém, perdeu importância para a $\mathrm{AD}$ e o Copei quando passaram a eleger muitos menos parlamentares ou nem sequer entraram na disputa.

As organizações da sociedade civil tampouco conseguiram que as suas intenções com a adoção do sistema misto se concretizassem. Shugart (2001) e Crisp e Rey (2001) consideram que a descentralização dos processos de seleção de candidatos pouco avançou. A determinação legal de que haja eleições internas também não foi suficiente porque, como se limitou a exigir processos fechados, os partidos ainda preservaram poder de regulação. Assim, as principais agrupações continuaram a definir os integrantes das suas listas e a influenciar o resultado porque a ordem de aparição dos nomes seguiu como determinante para a eleição de uma parcela significativa da câmara baixa. Além disso, a distribuição final das cadeiras não deixou de partir da votação proporcional em nível estadual.

A intenção de diminuir a influência dos partidos sobre as candidaturas e o resultado final com a introdução de distritos nominais passou a esbarrar mais recentemente em um procedimento informal, a já mencionada utilização de siglas auxiliares, os partidos morochos. Com eles, as principais forças podem optar por não ter candidatos próprios nos distritos nominais e evitar que os eleitos nessas disputas diminuam as vagas obtidas por suas listas.

Mesmo nos distritos nominais, entretanto, as principais agrupações não ficaram sem capacidade de influência. A tática de, a fim de eleger uma bancada maior, pedir o voto a um candidato que aparece sob outra sigla foi mais um passo para preservar a influência, já que os partidos são os maiores interessados e responsáveis por essa estratégia. O uso desse procedimento generalizouse nas eleições parlamentares de 2005, mas serve apenas às agrupações com força suficiente para 
conquistar cadeiras por listas e distritos. Um partido que não elege ninguém por suas listas não tem a quem somar o Deputado eleito nominalmente por uma sigla auxiliar.

Para o estabelecimento de uma relação mais próxima entre cidadãos e deputados - outra intenção das organizações da sociedade civil Kulisheck e Crisp (2001, p. 430) consideram que o sistema misto também não funcionou. Segundo eles, os eleitos nos distritos nominais não tiveram incentivos para desenvolver um grau maior de satisfação das demandas dos seus votantes, pois continuaram a ter de preocupar-se em responder mais aos seus partidos, já que o processo de seleção de candidatos manteve-se muito centralizado.

As organizações da sociedade civil viram frustradas suas intenções no nível em que almejavam, mas é claro que, com a introdução dos distritos nominais, na comparação com a situação anterior, conseguiram em algum grau diminuir a influência dos partidos sobre o resultado final e aumentar a responsividade dos deputados eleitos perante os cidadãos.

\section{CONCLUSÕES}

As intenções dos principais atores que participaram da definição de um sistema eleitoral misto na Venezuela, portanto, não se concretizaram. Os partidos tradicionais não conseguiram manter-se como dominantes e, pelos resultados das eleições na Venezuela desde 1993, correm o risco mesmo de tornarem-se cada vez menos relevantes no cenário político.

As organizações da sociedade civil também não alcançaram os resultados que esperavam com a nova fórmula. Os partidos continuaram a centralizar o processo de seleção de candidatos e a ter influência sobre o resultado final das eleições para deputado, assim como os parlamentares eleitos não deixaram de ser mais responsivos a suas agrupações do que aos cidadãos.

Shugart (2001, p. 184-190) ajuda a reforçar esse último ponto com sua classificação da eficiência dos sistemas eleitorais. Na dimensão intrapartidária, a Venezuela, que com as regras anteriores à reforma tinha o nível mais alto de centralização entre os países analisados por Shugart, passa da pontuação de 1 para a de $0,72^{5}$. Ou seja, continua a ter um valor alto e distante da eficiência e apenas transita da faixa dos sistemas hipercentralizados, na qual era a única representante, para a dos centrados nos partidos. Na dimensão interpartidária, é curioso notar que uma reforma que cria distritos com regra majoritária deixa a Venezuela mais representativa, passando da faixa dos majoritários para a dos representativos e perdendo eficiência ${ }^{6}$. Como o artigo de Shugart é de 2001, a explicação para esse resultado parece ser a introdução dos distritos multinominais a partir das eleições de 1998.

Este artigo argumentou que os principais atores viram frustradas suas intenções com a adoção de uma fórmula mista na Venezuela. Isso não significa que uma reforma como a venezuelana sempre estará destinada ao fracasso. As condições para que a $\mathrm{AD}$ e o Copei se mantivessem como dominantes já não eram propícias, independentemente do sistema eleitoral que viesse a ser implantado. A combinação de crises econômica e de credibilidade política a partir do final da década de 1980 no país contribuiu para minar as duas forças tradicionais. O exemplo da Venezuela mostra, porém, que a fórmula mista nem sempre é capaz de resolver os problemas identificados nas regras vigentes, como se considera em muitos países em que é defendida ou implantada.

\footnotetext{
5 A Venezuela é o único exemplo entre os sistemas mistos avaliados na dimensão intrapartidária em que não aparecem no texto uma pontuação para a parte majoritária e outra para a representativa. Assim, não fica claro como Shugart fixa o valor de 0,72 .

6 O critério principal de eficiência na dimensão interpartidária é a capacidade de formação de maiorias, o
}

João Carlos Amoroso Botelho (joaocarlosbotelho@hotmail.com) é Doutorando em Ciência Política na Universidade de Salamanca (Espanha) e pesquisador da Pontifícia Universidade Católica de São Paulo (PUC-SP). 


\section{REFERÊNCIAS BIBLIOGRÁFICAS}

ÁLVAREZ, A. E. 2003. La reforma del Estado antes y después de Chávez. In: ELLNER, S. \& HELLINGER, D. (orgs.). La política venezolana en la época de Chávez: clases, polarización y conflicto. Caracas: Nueva Sociedad.

CABALLERO, M. 2003. Las crisis de la Venezuela contemporánea (1903-1992). Caracas: Alfadil.

CRISP, B. F. \& REY, J. C. 2001. The Sources of Electoral Reform in Venezuela. In: SHUGART, M. S. \& WATTEMBERG, M. P. (eds.). Mixed-Member Electoral Systems: The Best of Both Worlds? Oxford: Oxford University.

ELLNER, S. \& HELLINGER, D. (orgs.). 2003. La política venezolana en la época de Chávez: clases, polarización e conflicto. Caracas: Nueva Sociedad.

HELLINGER, D. 2003. Visión política general: la caída del puntofijismo y el surgimiento del chavismo. In: ELLNER, S. \& HELLINGER, D. (orgs.). La política venezolana en la época de Chávez: clases, polarización y conflicto.
Caracas: Nueva Sociedad.

KULISHECK, M. R. \& CRISP, B. F. 2001. The Legislative Consequences of MMP Electoral Rules in Venezuela. In: SHUGART, M. S. \& WATTEMBERG, M. P. (eds.). Mixed-Member Electoral Systems: The Best of Both Worlds? Oxford: Oxford University.

MAINGON, T. 2004. Síntomas de la crisis y de la deslegitimación del sistema de partidos en Venezuela. Artigo apresentado no XXV Congresso Internacional de la Latin American Studies Association, ocurrido en Las Vegas (Estados Unidos), de 6 a 8 de octubre. Digit.

MOLINA, J. E. 2002. The Presidential and Parliamentary Elections of the Bolivarian Revolution in Venezuela: Change and Continuity (1998-2000). Bulletin of Latin American Research, London, v. 21, n. 2, p. 219-247, Apr.

REY, J. C. 1972. El sistema de partidos venezolano. Politeia, Caracas, n. 1, p. 175-230.

SHUGART, M. S. 2001. Electoral "Efficiency" and the Move to Mixed-Member Systems. Electoral Studies, Amsterdam, v. 20, n. 2, p. 173-193, June.

\section{OUTRAFONTE}

VENEZUELA. 2000. Constitución de la Repúbli- ca Bolivariana de Venezuela. Caracas: Imprenta Nacional. 


\section{SYSTEM IN VENEZUELA}

\section{João Carlos Amoroso Botelho}

ABSTRACT: This article attempts to evaluate whether the adoption of a mixed electoral system for the lower House in Venezuela, as of the 1993 elections, attained the results that the main actors involved in planning and implementing it were expecting. It is not our intention to defend any particular type of electoral system nor to point out the advantages and disadvantages of each type. Our goal is simply to evaluate the results of one case in which the mixed system was adopted and compare them to what actors involved in the changes were actually expecting. It is only through rigorous analysis along these lines that we can discover whether in practice expectations were fulfilled or frustrated. Although it would be possible to anticipate our evaluation, this would not provide the empirical foundations that an exercise such as the one we present here has. Work that constrasts actors' intentions with the results of the implantation of a mixed system is important since, dealing with an uncommon formula whose results are little known outside of specialists' circles, in many countries (Brazil included) this system has been assumed to be a solution to the problems that have been detected under currently-existing ones. What we will attempt to show here is that, based on the Venezuelan example, in practice things tend to be more complicated. Our working hypothesis is that expectations have been frustrated, both for those who sought to decrease the influence of parties on the definition of the candidates and elected parliament members and over representatives' actions, as well as for those belonging to traditional political groups seeking to preserve their dominance.

KEYWORDS: Venezuela; mixed electoral systems; actors’ intentions; lower House.

\section{LES INTENTIONS DES ACTEURS ET LES RÉSULTATS DE LA MISE EM PLACE DU SYSTÈME ÉLECTORAL MIXTE AU VÉNÉZUELA}

\section{João Carlos Amoroso Botelho}

Cet article évalue si l'adoption d'un sytème électoral mixte pour la chambre basse au Vénézuela, à partir des élections de 1993, a atteint les résultats prévus par les principaux acteurs participant aux processus de sa conception et de sa mise en place. Il n'existe pas l'intention de prôner pour l'un ou l'autre système électoral ni de montrer les avantages et les inconvénients de chaque type. Le seul objectif est celui d'évaluer les résultats d'un cas d'adoption d'un système mixte et de l'opposer aux attentes des acteurs. C'est au moyen d'une analyse stricte dans ce sens qu'il faut faire pour savoir si vraiment les expectatives ont eté atteintes ou si elles ont été frustrées. Une évaluation préalable serait également possible, mas cela ne représenterait pas de fondements empiriques comme celui de ce travail-ci. Un article opposant les intentions des acteurs et les résultats de la mise en place d'un système mixte est important parce que, comme il s'agit d'une formule moins courante dont les résultats sont peu connus en dehors des cercles plus spécialisés, son adoption est considérée dans plusieurs pays, voire au Brésil, comme la solution pour les problèmes identifiés dans les règles en vigueur. À l'instar du cas vénézuélien, on essayera de montrer que dans la pratique cela ne se produit pas toujours de cette façon. L’hypothèse est que les attentes ont été frustrées, aussi bien de la part de ceux qui cherchaient à diminuer l'influence des partis sur la définition des candidats et des parlementaires élus à chaque élection et sur l'acton de leurs députés, que de la part des groupes politiques traditionnels qui avaient l'intention de demeurer dominants.

MOTS-CLÉS : Vénézuela ; systèmes électoraux mixtes ; intentions des acteurs ; chambre basse. 